\title{
Assessment of the dietary intake of total flavan-3-ols, monomeric flavan-3-ols, proanthocyanidins and theaflavins in the European Union
}

\author{
Anna Vogiatzoglou ${ }^{1}$, Angela A. Mulligan ${ }^{2}$, Robert N. Luben ${ }^{2}$, Marleen A. H. Lentjes ${ }^{2}$, Christian Heiss ${ }^{3}$, \\ Malte Kelm ${ }^{3}$, Marc W. Merx ${ }^{3}$, Jeremy P. E. Spencer ${ }^{1}$, Hagen Schroeter ${ }^{4}$ and Gunter G. C. Kuhnle ${ }^{1,2_{*}}$ \\ ${ }^{1}$ Department of Food \& Nutritional Sciences, University of Reading, Reading RG6 6AP, UK \\ ${ }^{2}$ Department of Public Health and Primary Care, University of Cambridge, Cambridge, UK \\ ${ }^{3}$ Division of Cardiology, Pulmonology and Vascular Medicine, Medical Faculty, University of Düsseldorf, \\ Düsseldorf, Germany \\ ${ }^{4}$ Mars, Inc., McLean, VA 22101, USA \\ (Submitted 11 June 2013 - Final revision received 16 October 2013 - Accepted 29 October 2013 - First published online 13 December 2013)
}

\section{Abstract}

Dietary interventions with flavan-3-ols have shown beneficial effects on vascular function. The translation of these findings into the context of the health of the general public requires detailed information on habitual dietary intake. However, only limited data are currently available for European populations. Therefore, in the present study, we assessed the habitual intake of flavan-3-ol monomers, proanthocyanidins (PA) and theaflavins in the European Union (EU) and determined their main food sources using the EFSA (European Food Safety Authority) Comprehensive European Food Consumption Database. Data for adults aged 18-64 years were available from fourteen European countries, and intake was determined using the FLAVIOLA Flavanol Food Composition Database, developed for the present study and based on the latest US Department of Agriculture and Phenol-Explorer databases. The mean habitual intake of flavan-3-ol monomers, theaflavins and PA ranged from $181 \mathrm{mg} / \mathrm{d}$ (Czech Republic) to $793 \mathrm{mg} / \mathrm{d}$ (Ireland). The highest intakes of flavan-3-ol monomers and theaflavins were observed in Ireland $(191 / 505 \mathrm{mg} / \mathrm{d})$ and the lowest intakes in Spain $(24 / 9 \mathrm{mg} / \mathrm{d})$. In contrast, the daily intake of PA was highest in Spain $(175 \mathrm{mg} / \mathrm{d})$ and lowest in The Netherlands $(96 \mathrm{mg} / \mathrm{d})$. Main sources were tea $(62 \%)$, pome fruits (11\%), berries (3\%) and cocoa products (3\%). Tea was the major single contributor to monomer intake (75\%), followed by pome fruits (6\%). Pome fruits were also the main source of PA $(28 \%)$. The present study provides important data on the population-based intake of flavanols in the EU and demonstrates that dietary intake amounts for flavan-3-ol monomers, PA and theaflavins vary significantly across European countries. The average habitual intake of flavan-3-ols is considerably below the amounts used in most dietary intervention studies.

Key words: Flavanols: Flavan-3-ol monomers: Procyanidins: Theaflavins: Dietary intake: European Food Safety Authority

Flavanols are a structurally complex subclass of flavonoids that are present in a number of foods such as pome fruits (e.g. apples and pears), legumes, cocoa, tea and wine. Dietary intervention studies have shown that flavanols can have a beneficial effect on vascular function and could, therefore, reduce the risk of $\mathrm{CVD}^{(1-3)}$; indeed, the European Food Safety Authority (EFSA) has recently approved a health claim for flavanols ${ }^{(4)}$. However, flavanols are a complex group of phytonutrients, often considered to include free and gallated flavan-3-ol monomers and oligomeric and polymeric compounds known as proanthocyanidins (PA), as well as other derivatives, such as theaflavins and thearubigins ${ }^{(5)}$. These compounds differ considerably not only in their structural and functional properties, but also in their metabolism and bioavailability ${ }^{(5,6)}$.

While dietary intervention studies have been able to show beneficial effects, results from observational studies have been more ambiguous and inconsistent ${ }^{(7,8)}$. This can be explained not only by lower intake values in observational studies, but also by differences in the types of flavanols used. Dietary intervention studies have used mainly flavanols derived from specific foods, such as cocoa and grape seed extracts $^{(9)}$, and have, therefore, focused on very specific compounds. Conversely, in observational studies, the intake of flavan-3-ols has often been calculated as that of all flavan-3ols, even though the main contributor to total flavan-3-ol

Abbreviations: DP, degree of polymerisation; EFSA, European Food Safety Authority; EPIC, European Prospective Investigation into Cancer and Nutrition; EU, European Union; PA, proanthocyanidin.

* Corresponding author: G. G. C. Kuhnle, fax +44 118378 7708, email g.g.kuhnle@reading.ac.uk 
intake in the general public, theaflavins, is found neither in cocoa powder nor in grape seeds.

To investigate the potential health effects of flavanols in the general public and to determine whether results from intervention studies could be translated into dietary recommendations, it is important to obtain accurate information on habitual intake and main dietary sources. However, the information currently available $\mathrm{e}^{(10-15)}$ is limited, as it is mainly based on observational studies, which are often not representative of the general public ${ }^{(7,14,16-23)}$. Furthermore, differences in the interpretation of flavan-3-ols in the nomenclature make comparisons difficult. Thus, currently available information on the estimated dietary intake of flavanols varies widely and there is a paucity of reliable information on intake in the general public. Indeed, comprehensive data on flavan-3-ol intake in a representative sample of the European population are currently not available.

New food composition databases on flavonoids developed recently $^{(24-26)}$ have opened a new approach for the estimation of dietary flavanol intake and the assessment of potential health benefits. In the present study, we used these databases to develop the FLAVIOLA Flavanol Food Composition Database, containing information on the flavanol content of more than 3000 different foods. Using this database and the recently published Comprehensive European Food Consumption Database, we determined the habitual dietary intake of flavanols in a representative sample of European adults in fourteen European countries.

\section{Subjects and methods}

The EFSA Comprehensive European Food Consumption Database is a unique tool that has been built from existing national information on food consumption. Food consumption data for adults aged 18-64 years from twenty-one surveys (approximately 30000 individuals) are available for fourteen countries $^{(27)}$. Information concerning the methodologies used in each survey is given in Table S1 (available online). Food consumption statistics are reported in $\mathrm{g} / \mathrm{d}$ and for chronic consumption. For each country, consumption data are given according to the first (twenty categories) and second (140 categories) levels of the FoodEx system and for the total population ${ }^{(28)}$. The hierarchical food classification system 'FoodEx', developed by the EFSA, was used to codify all the food items.

To estimate the intake of flavan-3-ols in Europe, we developed the FLAVIOLA Flavanol Food Composition Database containing food composition data for approximately 3000 food items. (More information on the database can be found on the website of the FLAVIOLA project, http://www.flaviola. org) The mean values of each flavan-3-ol compound are reported as $\mathrm{mg} / 100 \mathrm{~g}$ of fresh weight of edible portion of food. This database is based on the USDA (US Department of Agriculture) Database for the Flavonoid Content of Selected Foods $^{(26)}$ and the PA Content of Selected Foods ${ }^{(25)}$, expanded with values from the Phenol-Explorer, a comprehensive database on the polyphenol content of foods ${ }^{(24)}$. These databases are the most up-to-date databases on flavonoids and polyphenols and include information on 500, 205 and 456 food items for flavonoids ${ }^{(26)}, \mathrm{PA}^{(25)}$ and polyphenols ${ }^{(24)}$, respectively.

We expanded and completed the FLAVIOLA Flavanol Food Composition Database using DINER (Data Into Nutrients for Epidemiological Research), a food database created for the EPIC (European Prospective Investigation into Cancer and Nutrition)-Norfolk study ${ }^{(29)}$. The EPIC-Norfolk database was used for the calculation of the estimated flavan-3-ol content of approximately 2500 food items ( $82 \%$ of the 3000 total foods). The flavan-3-ol content of food preparations was calculated using approximately 800 recipes; retention and cooking factors for approximately 500 food items were used to estimate the effect of processing (e.g. frying, boiling and roasting) ${ }^{(30-32)}$. When information on the ingredients of commercial food products was provided by the manufacturers, their flavan-3-ol content was also calculated; where no information was available, products were matched to similar ones if possible. Food items thought not to contain significant levels of flavanols (fish, meat and eggs) were treated as logical zeros and omitted from the database. Dietary intake was estimated for three major

Table 1. Estimated mean and median flavan-3-ol intakes (mg/d) for adults in the EFSA (European Food Safety Authority) Comprehensive European Food Consumption Database

\begin{tabular}{|c|c|c|c|c|c|c|c|c|}
\hline & \multicolumn{2}{|c|}{ Total flavan-3-ols } & \multicolumn{2}{|c|}{ Flavan-3-ol monomers } & \multicolumn{2}{|c|}{ Proanthocyanidins } & \multicolumn{2}{|c|}{ Theaflavins } \\
\hline & Mean & Median & Mean & Median & Mean & Median & Mean & Median \\
\hline Belgium & 229 & $5 \cdot 2$ & 44.6 & 1 & $109 \cdot 3$ & 4.2 & $75 \cdot 1$ & 0 \\
\hline Czech Republic & $180 \cdot 8$ & 69.4 & 30.9 & $15 \cdot 4$ & $106 \cdot 6$ & $20 \cdot 8$ & 43.3 & 33.2 \\
\hline Denmark & 318.9 & 48.5 & $68 \cdot 1$ & 9.5 & 116 & 38.9 & 134.9 & 0 \\
\hline Finland & $276 \cdot 6$ & $6 \cdot 2$ & $56 \cdot 1$ & 3 & $115 \cdot 2$ & $3 \cdot 2$ & $105 \cdot 3$ & 0 \\
\hline France & 289.9 & 23.8 & 53 & 4 & 143.9 & $19 \cdot 8$ & 93 & 0 \\
\hline Germany & 503.5 & $5 \cdot 7$ & $111 \cdot 3$ & $1 \cdot 1$ & 143.5 & $4 \cdot 6$ & 248.7 & 0 \\
\hline Hungary & 355 & $187 \cdot 2$ & 68.4 & 38.5 & 141.5 & 65.4 & $145 \cdot 1$ & 83.3 \\
\hline Ireland & $792 \cdot 9$ & 701.5 & $190 \cdot 7$ & 174.5 & $97 \cdot 5$ & $45 \cdot 8$ & $504 \cdot 7$ & $481 \cdot 2$ \\
\hline Italy & 223.7 & $40 \cdot 6$ & $28 \cdot 8$ & 5.4 & 161.4 & $35 \cdot 2$ & 33.5 & 0 \\
\hline Latvia & 348.5 & $182 \cdot 6$ & $72 \cdot 2$ & $45 \cdot 1$ & 112.5 & $12 \cdot 5$ & 163.8 & 125 \\
\hline The Netherlands & $581 \cdot 3$ & $321 \cdot 7$ & 138.5 & 79.9 & 96 & $19 \cdot 6$ & $346 \cdot 8$ & $222 \cdot 2$ \\
\hline Spain & 208 & 43.6 & 24 & 7.4 & $174 \cdot 7$ & $36 \cdot 2$ & 9.2 & 0 \\
\hline Sweden & $252 \cdot 2$ & $72 \cdot 4$ & 52.4 & $14 \cdot 2$ & $100 \cdot 4$ & 34.4 & 99.4 & $23 \cdot 8$ \\
\hline UK & $600 \cdot 3$ & $408 \cdot 1$ & 139.8 & 100 & $108 \cdot 7$ & $36 \cdot 6$ & 351.8 & 271.5 \\
\hline
\end{tabular}



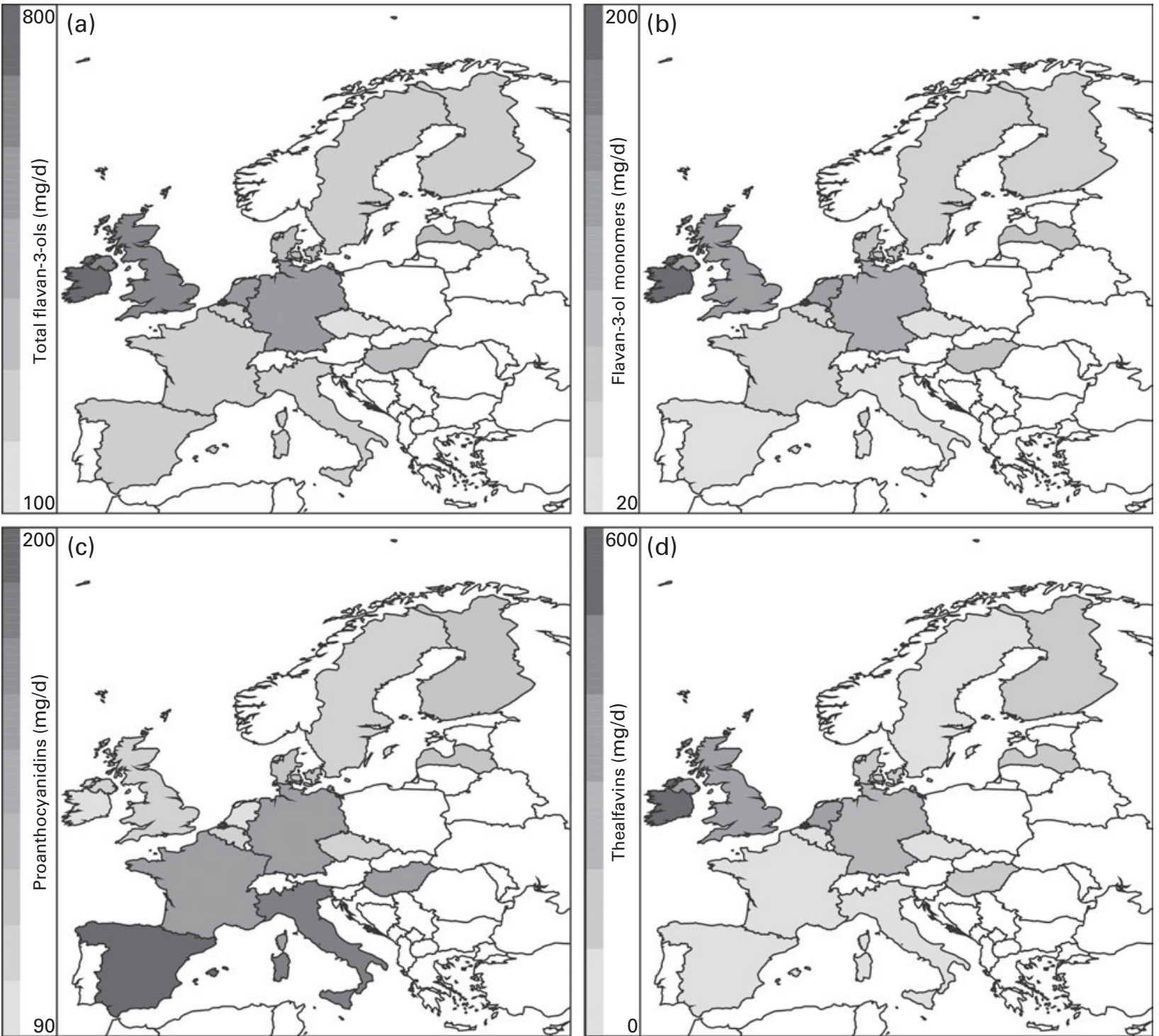

Fig. 1. Estimated intakes (mg/d) of (a) total flavan-3-ols, (b) flavan-3-ol monomers, (c) proanthocyanidins and (d) theaflavins in the European Union.

flavan-3-ol subgroups (flavan-3-ol monomers, PA and theaflavins) and their seventeen component flavanols: flavan3-ol monomers ((-)-epicatechin, (-)-epicatechin-3'-gallate, $(+)$-catechin, (-)-epigallocatechin, (-)-epigallocatechin3'-gallate, $(+)$-gallocatechin and $(+)$-catechin-3'-gallate); theaflavins (theaflavin, thearubigins, theaflavin-3,3'-digallate, theaflavin-3'-gallate and theaflavin-3-gallate); PA (dimers, trimers, tetramers-hexamers, heptamers-decamers and $>$ decamers)

The intake of flavan-3-ols was calculated based on the consumption data for each of the 140 categories of the second level of the FoodEx system. As many categories contain

Table 2. Estimated mean and median flavan-3-ol intakes $(\mathrm{mg} / \mathrm{d})$ for adults in the three European regions in the EFSA (European Food Safety Authority) Comprehensive European Food Consumption Database*

\begin{tabular}{|c|c|c|c|c|c|c|c|c|}
\hline \multirow[b]{2}{*}{ Region } & \multicolumn{2}{|c|}{ Flavan-3-ols } & \multicolumn{2}{|c|}{$\begin{array}{l}\text { Flavan-3-ol } \\
\text { monomers }\end{array}$} & \multicolumn{2}{|c|}{$\begin{array}{l}\text { Proantho- } \\
\text { cyanidins }\end{array}$} & \multicolumn{2}{|c|}{ Theaflavins } \\
\hline & Mean & Median & Mean & Median & Mean & Median & Mean & Median \\
\hline Southern & 240.5 & 36 & $35 \cdot 2$ & 5.6 & 160 & 30.4 & $45 \cdot 3$ & 0 \\
\hline Central & 448.9 & $235 \cdot 2$ & 99.5 & $56 \cdot 9$ & 114.5 & $26 \cdot 2$ & 234.9 & 152 \\
\hline Northern & $282 \cdot 6$ & $42 \cdot 3$ & $58 \cdot 8$ & 8.9 & 110.5 & $25 \cdot 5$ & $113 \cdot 2$ & 7.9 \\
\hline
\end{tabular}

* Southern: Spain, France and Italy; Central: Belgium, Czech Republic, Germany, Hungary, Ireland, Latvia, The Netherlands and UK; Northern: Denmark, Finland and Sweden. 
more than one flavan-3-ol-containing food, a weighted average was used to determine the flavan-3-ol content in each of these categories. Using a weighted average was necessary, because rarely consumed foods with high flavan-3-ol-content, for example, some berries, in a category could result in an overestimation of intake. The weighing factors were determined using the FAO food balance sheets for the year of the survey and the frequency of food consumption from the EPIC-Norfolk study (see Table S2, available online). The total flavan-3-ol content of each category was calculated as the sum of the products of the weighing factor and flavan-3-ol content of each individual food included in the respective category.

The estimated mean and median values of flavan-3-ol intake, as well as a range of minimum and maximum values, based on the reported upper and lower ranges of food composition are reported. Values given in further tables are based on mean intake values to allow for comparison with other studies. The European countries represented in the EFSA comprehensive database were grouped into regions to allow for observations in each distinctive area (Southern: Italy, Spain and France; Central: Belgium, Czech Republic, Germany, Hungary, Ireland, Latvia, The Netherlands and UK; Northern: Denmark, Finland and Sweden). Unless indicated otherwise, all the data are given as the mean daily intake of respective flavan-3-ols.

\section{Results}

\section{Estimated daily flavan-3-ol intake}

The estimated mean and median daily intakes $(\mathrm{mg} / \mathrm{d})$ of total flavanols as well as of their subgroups for adults in the European Union (EU) are given in Table 1 and Fig. 1. The mean intake of total flavan-3-ols ranged from $181 \mathrm{mg} / \mathrm{d}$ (Czech Republic) to $793 \mathrm{mg} / \mathrm{d}$ (Ireland), whereas the median intake ranged from $5 \mathrm{mg} / \mathrm{d}$ (Belgium) to $702 \mathrm{mg} / \mathrm{d}$ (Ireland). The average intake of flavan-3-ols was $369 \mathrm{mg} / \mathrm{d}$ in the EU. The mean intake of the different flavan-3-ol groups was $77 \mathrm{mg} / \mathrm{d}$ for monomers, $123 \mathrm{mg} / \mathrm{d}$ for PA and $168 \mathrm{mg} / \mathrm{d}$ for theaflavins. The highest intake of monomers was observed in Ireland $(191 \mathrm{mg} / \mathrm{d})$ and the lowest in Spain $(24 \mathrm{mg} / \mathrm{d})$. The intake of theaflavins was highest in Ireland $(505 \mathrm{mg} / \mathrm{d})$ and lowest in Spain $(9 \mathrm{mg} / \mathrm{d})$. In contrast, the daily intake of PA was highest in Spain $(175 \mathrm{mg} / \mathrm{d})$ and lowest in The Netherlands $(96 \mathrm{mg} / \mathrm{d})$. The estimated mean and median intakes $(\mathrm{mg} / \mathrm{d})$ of total flavan-3-ols and flavan-3-ol subgroups for adults in the three European regions are summarised in Table 2. The mean intake of total flavan3-ols was $241 \mathrm{mg} / \mathrm{d}$ in the Southern region, $449 \mathrm{mg} / \mathrm{d}$ in the Central region and $283 \mathrm{mg} / \mathrm{d}$ in the Northern region.

The mean daily intake of individual monomers, PA and theaflavins and their quantitative contribution to total intake are given in Table 3 and Fig. 2. Theaflavins were the major contributors to total flavan-3-ol intake (46\%) in the EU, followed by PA (34\%) and monomers (21\%). The main flavan-3-ol groups in the Southern region were PA (67\%), whereas in the Central and Northern regions, theaflavins were the main contributors (52 and $40 \%$, respectively).
(⿻)

언 운 (ब)

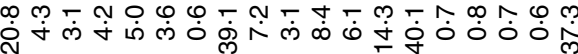
옹

焉 ब

$\infty$ n

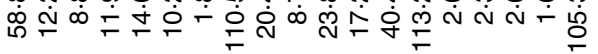
造

옝 ते

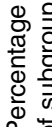
बै

弯

ما

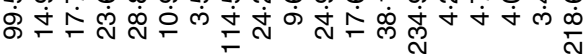

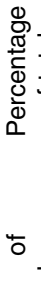
立

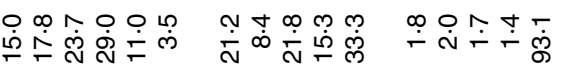
人ém,

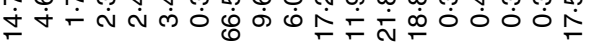

No

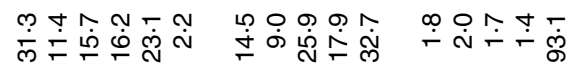

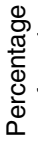

のरம

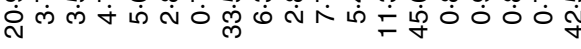

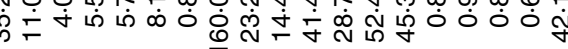

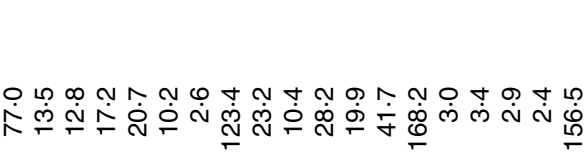

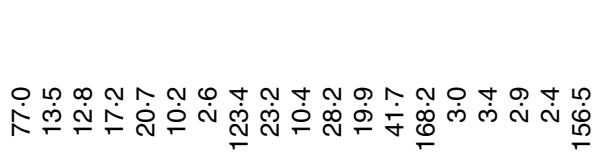

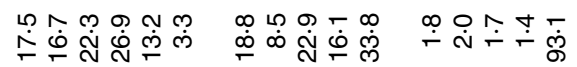

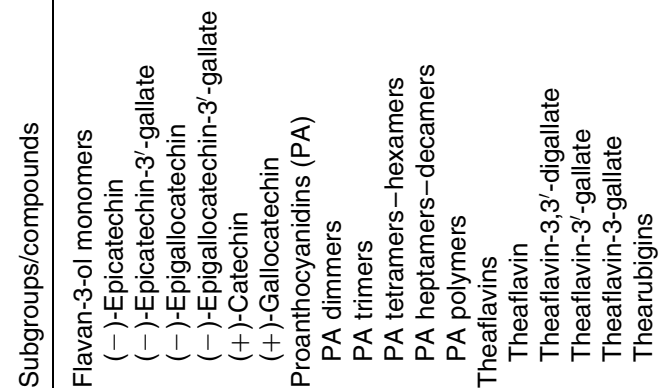



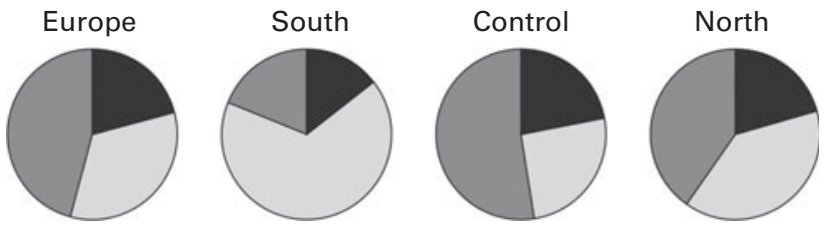

Fig. 2. Relative contribution of flavan-3-ol subgroups to total flavan-3-ol intake in Europe and the Southern, Central and Northern subregions. E, Flavan-3-ol monomers; $\square$, proanthocyanidins; $\square$, theaflavins.

The individual compounds with the highest intakes were thearubigins (43\%) and PA polymers (11\%), followed by PA (tetramers-hexamers) (8\%). This pattern was similar for the Central and Northern regions, whereas in the Southern region, PA polymers were the main contributors to flavan-3ol intake (22\%).

\section{Major dietary flavan-3-ol sources}

The main sources of dietary total flavan-3-ols in the EU were tea $(62 \%)$, pome fruits $(11 \%)$, berries $(3 \%)$, cocoa products $(3 \%)$ and stone fruits (3\%) (Table 4). Tea was the main contributor to monomer intake $(75 \%)$, followed by pome fruits $(6 \%)$, whereas pome fruits were the main sources of PA (28\%). Table 5 summarises the contributions of the main food groups to flavan-3-ol intake by country. The main sources of total flavan-3-ols were non-alcoholic beverages (46\% in France to $89 \%$ in Ireland), with tea being the major source for most countries. Fruits were the main contributors to flavan-3-ol intake in Italy and Spain (42 and 45\% of total intake, respectively). Alcoholic beverages were also an important source of flavanols in some other countries, with wine being the main contributor to total flavan-3-ol intake within the group of alcoholic beverages.

The main food sources of flavan-3-ols in the Southern region were fruits (38\%) and non-alcoholic beverages (23\%) (Table 6 and Fig. 3). In the Central region, non-alcoholic beverages were the major source of total flavan-3-ols (62\%), followed by fruits (19\%). Non-alcoholic beverages were also the main contributors to total flavan-3-ol intake in the Northern region $(56 \%)$, with fruits making a significant contribution to flavan-3-ol intake (24\%). The difference in intakes between European regions was due to variations in tea consumption. The major source of total flavan-3-ols within the group of fruits was pome fruits in all the regions; however, the other important sources of flavan-3-ols varied according to region. In the Southern region, stone fruits were the second most important source of flavan-3-ols, whereas in the Northern region, berries were the second most significant source of flavan-3-ols within the group of fruits.

\section{Discussion}

In the present study, we estimated the habitual intake of flavan-3-ols and their major food sources in the adult European population. An important strength is the FLAVIOLA Flavanol Food Composition Database, which has been developed for the present study: it is based on an amalgamation of the most recent food composition data from the USDA Database and those from the Phenol-Explorer ${ }^{(24-26)}$, augmented by data from the EPIC-Norfolk food database, DINER ${ }^{(29)}$, which provides information on recipes and processing effects. With more than 3000 food items, the FLAVIOLA database is one of the most comprehensive food composition databases for flavanols available. The provision of upper and lower estimates of intake based on the variability of

Table 4. Major food sources of dietary total and individual flavan-3-ols in the EFSA (European Food Safety Authority) Comprehensive European Food Consumption Database

\begin{tabular}{|c|c|c|c|}
\hline Compounds & Intake $(\mathrm{mg} / \mathrm{d})$ & Food or food group & $\%$ \\
\hline \multirow[t]{5}{*}{ Total flavan-3-ols } & $230 \cdot 1$ & Tea (infusion) & $62 \cdot 4$ \\
\hline & $38 \cdot 7$ & Pome fruits & $10 \cdot 5$ \\
\hline & $12 \cdot 6$ & Berries and small fruits* & 3.4 \\
\hline & $11 \cdot 6$ & Cocoa beans and cocoa products & $3 \cdot 1$ \\
\hline & $10 \cdot 9$ & Stone fruits & 2.9 \\
\hline \multirow[t]{5}{*}{ Flavan-3-ol monomers } & $57 \cdot 9$ & Tea (infusion) & $75 \cdot 1$ \\
\hline & $4 \cdot 2$ & Pome fruits & 5.5 \\
\hline & $2 \cdot 0$ & Wine & $2 \cdot 6$ \\
\hline & 1.4 & Berries and small fruits* & 1.9 \\
\hline & $1 \cdot 2$ & Fruit juice & $1 \cdot 2$ \\
\hline \multirow[t]{5}{*}{ Proanthocyanidins } & 34.5 & Pome fruits & $27 \cdot 9$ \\
\hline & $11 \cdot 2$ & Berries and small fruits* & $9 \cdot 1$ \\
\hline & $10 \cdot 8$ & Cocoa beans and cocoa products & $8 \cdot 8$ \\
\hline & $10 \cdot 1$ & Stone fruits & $8 \cdot 2$ \\
\hline & $7 \cdot 7$ & Tea (infusion) & $6 \cdot 3$ \\
\hline \multirow[t]{2}{*}{ Theaflavins } & $164 \cdot 5$ & Tea (infusion) & $97 \cdot 8$ \\
\hline & 3.7 & Tea and herbs for infusions (solid) & $2 \cdot 2$ \\
\hline
\end{tabular}

* Small fruits according to the definition used by the EFSA in the FoodEx system: azarole (Mediterranean medlar); bearberries; bilberries or whortleberries; blackberries; blueberries; boysenberries; cloudberries; cranberries; crowberries; currants (red, black and white); dewberries; elderberries; gooseberries; huckleberries; jabuticabas; lingonberries; loganberries; mulberries; physalis; raspberries; rose hips; salmonberries; sea buckthorns; strawberries; strawberry trees; table grapes; thimbleberries; wine grapes; wineberries. 
food composition data (see Table S3, available online) allows for a better assessment of the likely range of intake values, in particular, to investigate potential health effects and make future recommendations.

There exist some methodological limitations that have to be taken into consideration when interpreting the results. The EFSA provides intake data for food groups, but not for individual foods, and thus food balance sheets and other information had to be used to address this gap and to improve the usability of the data available. Furthermore, differences in the dietary assessment methods (see Table S1, available online) are likely to introduce a certain degree of bias. Food records and $24 \mathrm{~h}$ recalls, the methods used in the present study, can result in over- and under-reporting of the intake of individual food items and thus in systematic bias. Calibration studies to adjust for this, as used, for example, in the EPIC study ${ }^{(33,34)}$, have not been conducted so far, but would be important to make better use of the data available. An additional limitation is the data available on food composition: these data are often based on a fairly small number of analysis reports and thus the paucity of standardised and fully validated analytical methods ${ }^{(6,35)}$ introduces additional variability. There is also limited information available on food preparation methods, which is, in particular, important for foods such as tea, for which brewing time and preparation method may affect the flavan-3-ol content. In the absence of such information, the average food composition value is used.

Despite these limitations, the present study provides the most accurate data on flavan-3-ol intake in the EU that are currently available and, for the first time, allows to estimate the exposure of the European population to flavan-3-ols and to investigate the potential impact on health. A key strength of the present study is based on the fact that the food consumption data used emanated from representative surveys of the European population, thus reducing the selection bias often found in observational studies.

A comparison between flavanol intake values determined in the present study and data from other investigations is challenging, because of a significant divergence in the interpretation and application of flavanol nomenclature. The intake of flavan-3-ols in the EU determined in the present study was $77 \mathrm{mg} / \mathrm{d}$, which is lower than the values reported for the USA $(157 \mathrm{mg} / \mathrm{d})^{(10,13)}$, Japan $(380 \mathrm{mg} / \mathrm{d})^{(36)}$ and Australia $(422 \mathrm{mg} / \mathrm{d})^{(11)}$. However, the data obtained from Australia and the USA, but not from Japan, include those on theaflavins, flavanol derivatives mainly found in tea. The combined intake of flavan-3-ol monomers and theaflavins in Europe was $245 \mathrm{mg} / \mathrm{d}$ and thus higher than that in the USA. Differences in the interpretation of the nomenclature can, therefore, result in the over- or underestimation of intake. Within Europe, the highest intakes of total flavan-3-ols (monomers, $\mathrm{PA}$ and theaflavins) were observed in the Central region due to the high intake of tea, especially in countries with a tea culture, such as the UK and Ireland $(600$ and $793 \mathrm{mg} / \mathrm{d}$, respectively). Similar results were obtained in the EPIC study, where the highest intake was found in a UK cohort $(408 \mathrm{mg} / \mathrm{d})^{(23)}$, even though total intake was lower than that 
Table 6. Relative contribution (\%) of food groups and some main foods to the intake of total flavan-3-ols and groups of flavan-3-ols by European region

\begin{tabular}{|c|c|c|c|c|c|c|c|c|c|c|c|c|}
\hline & \multicolumn{3}{|c|}{ Total flavanols } & \multicolumn{3}{|c|}{ Total flavan-3-ol monomers } & \multicolumn{3}{|c|}{ Total proanthocyanidins } & \multicolumn{3}{|c|}{ Total theaflavins } \\
\hline & Southern & Central & Northern & Southern & Central & Northern & Southern & Central & Northern & Southern & Central & Northern \\
\hline Grains and grain-based products & 4.9 & 3.2 & 3.8 & 3.0 & 1.6 & 1.3 & $6 \cdot 8$ & 9.7 & 8.9 & 0.0 & 0.0 & 0.0 \\
\hline Vegetables and vegetable products & $14 \cdot 1$ & $6 \cdot 3$ & $2 \cdot 4$ & $10 \cdot 0$ & 6.6 & 0.8 & $16 \cdot 1$ & $5 \cdot 7$ & 5.6 & $25 \cdot 0$ & $12 \cdot 6$ & 0.0 \\
\hline Tea and herbs for infusions & 1.5 & 4.0 & 0.0 & $3 \cdot 2$ & 5.8 & 0.0 & 0.0 & 0.0 & 0.0 & $25 \cdot 0$ & $12 \cdot 6$ & 0.0 \\
\hline Cocoa beans and cocoa products & $12 \cdot 6$ & $2 \cdot 3$ & $2 \cdot 4$ & $6 \cdot 7$ & 0.8 & 0.8 & $16 \cdot 1$ & $5 \cdot 7$ & 5.6 & 0.0 & 0.0 & 0.0 \\
\hline Legumes, nuts and oilseeds & 3.4 & 1.6 & $1 \cdot 1$ & $2 \cdot 6$ & 0.7 & 0.5 & 4.5 & $5 \cdot 0$ & $2 \cdot 6$ & 0.0 & 0.0 & 0.0 \\
\hline Fruit and fruit products & 37.9 & 18.5 & 24.4 & $31 \cdot 3$ & $10 \cdot 9$ & $14 \cdot 2$ & $49 \cdot 3$ & $47 \cdot 7$ & 54.6 & 0.0 & 0.0 & 0.0 \\
\hline Citrus fruits & 1.3 & 0.4 & $1 \cdot 2$ & $2 \cdot 0$ & 0.4 & 1.1 & 1.5 & $1 \cdot 1$ & 2.5 & 0.0 & 0.0 & 0.0 \\
\hline Pome fruits & $19 \cdot 1$ & $10 \cdot 8$ & 13.0 & $16 \cdot 0$ & $6 \cdot 0$ & $6 \cdot 8$ & 24.3 & $28 \cdot 0$ & 29.8 & 0.0 & 0.0 & 0.0 \\
\hline Stone fruits & 11.9 & $2 \cdot 1$ & $2 \cdot 0$ & $7 \cdot 2$ & 0.9 & 0.7 & $15 \cdot 7$ & $5 \cdot 3$ & 4.8 & 0.0 & 0.0 & 0.0 \\
\hline Berries and small fruits & 4.0 & 3.4 & $6 \cdot 8$ & 3.2 & 1.9 & 3.7 & $5 \cdot 6$ & 8.6 & 14.9 & 0.0 & 0.0 & 0.0 \\
\hline Miscellaneous fruits & 0.6 & 0.3 & 0.6 & 2.0 & 0.6 & $1 \cdot 1$ & 0.5 & 0.6 & 0.8 & 0.0 & 0.0 & 0.0 \\
\hline Meat and fish & 0.0 & 0.1 & 0.1 & 0.1 & 0.1 & 0.1 & $0 \cdot 1$ & 0.2 & 0.1 & 0.0 & 0.0 & 0.0 \\
\hline Milk and dairy products & 0.8 & 0.6 & 1.2 & 1.2 & 0.5 & $1 \cdot 1$ & 1.0 & 1.6 & 2.5 & 0.0 & 0.0 & 0.0 \\
\hline Sugar and confectionery & 1.9 & $2 \cdot 3$ & 3.2 & 1.7 & 1.4 & 1.8 & $2 \cdot 7$ & $7 \cdot 3$ & $7 \cdot 2$ & 0.0 & 0.0 & 0.0 \\
\hline Fruit and vegetable juices & 1.0 & 0.9 & $2 \cdot 0$ & 3.2 & $2 \cdot 0$ & 4.7 & 0.8 & 1.8 & $2 \cdot 6$ & 0.0 & 0.0 & 0.0 \\
\hline Non-alcoholic beverages & $22 \cdot 7$ & $61 \cdot 8$ & $56 \cdot 4$ & 35.9 & $70 \cdot 7$ & $68 \cdot 7$ & 1.7 & 10.5 & $5 \cdot 7$ & $75 \cdot 0$ & $87 \cdot 4$ & $100 \cdot 0$ \\
\hline Tea (infusion) & $22 \cdot 4$ & 61.5 & 55.9 & 35.4 & $70 \cdot 2$ & 67.5 & 1.4 & 9.9 & 4.8 & $75 \cdot 0$ & 87.4 & $100 \cdot 0$ \\
\hline Coffee (beverage) & 0.0 & 0.0 & 0.2 & 0.2 & 0.2 & 0.7 & 0.0 & 0.0 & 0.0 & 0.0 & 0.0 & 0.0 \\
\hline Cocoa beverage & 0.2 & 0.2 & 0.4 & 0.2 & 0.2 & 0.3 & 0.3 & 0.4 & 0.8 & 0.0 & 0.0 & 0.0 \\
\hline Alcoholic beverages & $5 \cdot 1$ & $2 \cdot 7$ & 4.2 & $9 \cdot 3$ & 4.5 & 5.8 & $5 \cdot 9$ & $5 \cdot 3$ & $7 \cdot 7$ & 0.0 & 0.0 & 0.0 \\
\hline Wine & 4.8 & $2 \cdot 0$ & 3.6 & $8 \cdot 0$ & $2 \cdot 4$ & 4.0 & $5 \cdot 8$ & 4.6 & $7 \cdot 2$ & 0.0 & 0.0 & 0.0 \\
\hline Beer and cider & 0.2 & 0.6 & 0.6 & $1 \cdot 1$ & $2 \cdot 0$ & 1.8 & 0.1 & 0.6 & 0.5 & 0.0 & 0.0 & 0.0 \\
\hline Herbs, spices and condiments & $7 \cdot 2$ & 1.0 & 0.1 & 0.3 & 0.2 & 0.2 & $10 \cdot 0$ & 2.5 & 0.1 & 0.0 & 0.0 & 0.0 \\
\hline Composite foods & 0.1 & 0.5 & 0.7 & 0.0 & 0.2 & 0.4 & 0.1 & 1.5 & 1.5 & 0.0 & 0.0 & 0.0 \\
\hline Snacks, desserts and other foods & 0.8 & 0.4 & 0.4 & 1.4 & 0.5 & 0.5 & 1.0 & $1 \cdot 2$ & 0.8 & 0.0 & 0.0 & 0.0 \\
\hline
\end{tabular}


in the present study, which can be explained by differences in the study population and dietary assessment methods.

For individual subclasses of flavanols also, there were differences with regard to previously reported data: for example, in a representative sample of the Dutch population, flavanol monomer intake was $56 \mathrm{mg} / \mathrm{d}^{(14)}$, which is lower than the values obtained both in the present study and at the EPIC centres of The Netherlands (139 and $89 \mathrm{mg} / \mathrm{d}$, respectively) ${ }^{\text {(23) }}$. However, this study included an age range (1-93 years) that was wider than that used in both the EPIC study (35-74 years) and the present study (18-64 years). Furthermore, the study relied on food composition data for only a limited number of foods, whereas both the EPIC study and the present study used more comprehensive databases. The intake of PA in the present study was lower than that in the EPIC study (e.g. in the UK: $109 v .198 \mathrm{mg} / \mathrm{d}$ ) ${ }^{(14)}$, and this could be explained by differences in the dietary patterns of participants of observational studies and a representative survey. The main sources of PA in both EPIC study and the present study were pome fruits. However, there were differences in other major sources, supporting different dietary patterns as an explanation for differences observed: while wine and stone fruits were important contributors to total intake in the EPIC study, berries and cocoa products were important contributors in the present study. Differences have also been observed in Scandinavian countries: the intake of flavan-3-ols in Denmark in the present study was almost twice that reported in the EPIC-Denmark study (203 v. $106 \mathrm{mg} / \mathrm{d})^{(23)}$, whereas that of PA was much lower $(116 v .237 \mathrm{mg} / \mathrm{d})$. Results from the representative Danish Household Consumption Survey ${ }^{(11,12)}$ indicate an average flavan-3-ol intake of $148 \mathrm{mg} / \mathrm{d}$; however, the present study used older data and the lower intake might be explained by differences in the food composition tables used. In countries of the Southern region (France, Italy and Spain), PA were the most important contributors to total flavanol intake. Although the amount of flavan-3-ols consumed was similar in the present study and other studies such as the EPIC study ${ }^{(23)}$ and the French SU.VI.MAX (Supplementation en Vitamines et Minéraux Antioxydants) study ${ }^{(37)}$, there were some discrepancies in the main sources. The EPIC study identified red wine and tea as the main sources of monomers in Spain, while the present study found pome fruits and cocoa products to be the major sources. A possible explanation for this discrepancy is the circumstance that data for the EPIC study had been collected 10 years earlier and dietary habits might have changed.

When stratified by regions, the intake of flavanols in the Central region was approximately 2-fold higher than that in the Southern region ( 451 and $242 \mathrm{mg} / \mathrm{d}$, respectively). Conversely, the intake of PA was found to be higher in the Southern region due to the higher intake of fruits. The main source of $\mathrm{PA}$ in the Southern region was pome fruits, similar to what

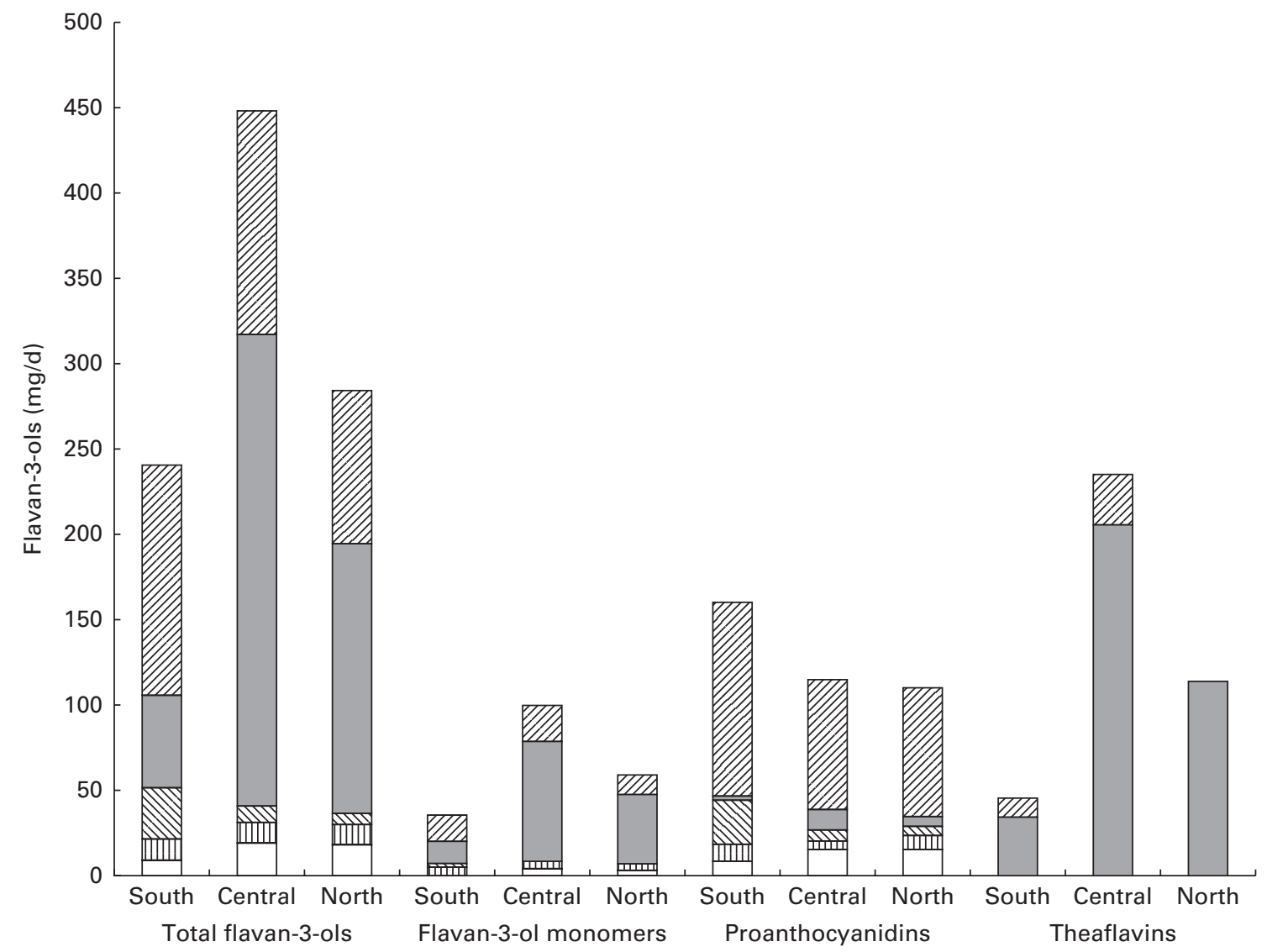

Fig. 3. Contribution of individual food groups to the intake of total flavan-3-ols and subgroups in the Southern, Central and Northern subregions. $\square$, Fruit and vegetables; $\square$, tea; $₫$, cocoa products; 四, alcoholic beverages; $\square$, other foods. 
was reported in the EPIC study ${ }^{(23,38)}$. The major sources of flavan-3-ols were similar for the Central and Northern regions, with tea being the main source, while in the Southern region, fruits, mainly pome and stone fruits, were the main sources. However, in the Southern and Central regions, the main source of flavan-3-ols within the group of fruits was pome fruits, while in the Northern region, berries were the most significant source. The main flavan-3-ol groups in the Southern region were PA (66\%), whereas in the Central and Northern regions, theaflavins were the most important sources (52 and $40 \%$, respectively). Monomers contributed $15 \%$ in the Southern region, $23 \%$ in the Central region and $21 \%$ in the Northern region.

A comparison of the mean and median intakes of flavan-3ols indicated large differences in the distribution of intakes in different countries. Median intake was lower for all the compounds, indicating a skewed distribution, but this difference was smallest in the Central region. The largest difference was found for theaflavins. While the difference between the mean and median intakes of flavan-3-ols and those of monomers in Ireland was approximately $10 \%$, it was almost 100-fold in Germany $(504 v .6 \mathrm{mg} / \mathrm{d}$ for total flavan-3-ols and $111 v \cdot 1 \cdot 1 \mathrm{mg} / \mathrm{d}$ for monomers); this is probably due to a large variation in tea consumption in Germany. For nutrients with a very skewed distribution of intake, a comparison of median and mean values is very important to avoid the over- or underestimation of exposure.
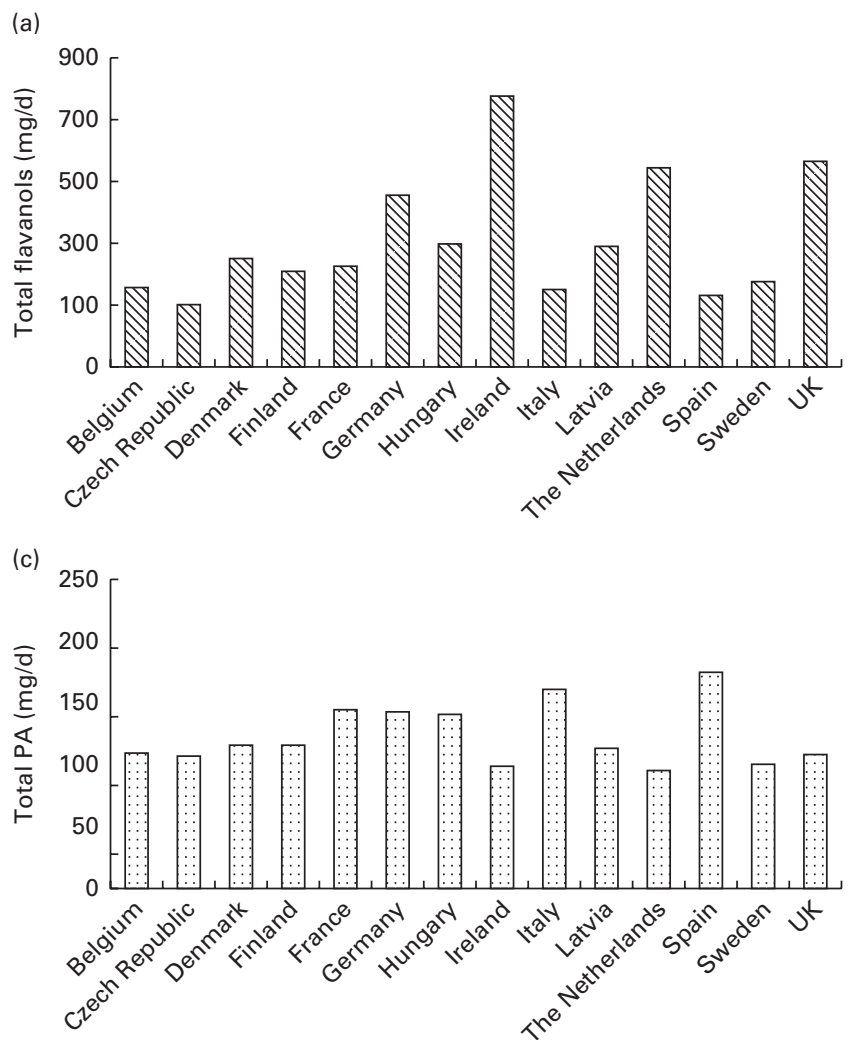

The dietary data obtained in the present study allow for a comparison of habitual intake in the general public with the amounts used in dietary intervention studies and thus the investigation of the potential impact of flavan-3-ol consumption on public health. However, flavan-3-ols used in many dietary intervention studies are not well characterised by compound-specific analyses and are mainly non-specifically described by their source, e.g. cocoa and grape seed extracts. Thus, in the absence of well-characterised foodstuffs and plant extracts, the absolute and relative content of individual flavanols is often not known ${ }^{(1)}$. Therefore, to facilitate meaningful outcome assessments, it is crucial to analytically characterise foods used in dietary interventions and to provide specific information with regard to the content and chemical identity of compounds hypothesised to be bioactive. Nevertheless, even the EFSA-approved health claim for cocoa flavanols ${ }^{(4)}$ - based on an unspecified increase of flow-mediated dilation - only refers to 'cocoa flavanols with a degree of polymerisation (DP) from 1 to 10'. As gallated compounds are not present in $\operatorname{cocoa}^{(25,26)}$, this apparently only includes epicatechin and catechin monomers, but food processing and other factors can result in epimerisation and may also affect the DP, all of which can affect bioavailability and bioactivity ${ }^{(39,40)}$. Similar difficulties apply to grape seed extracts, where there is a paucity of information apart from food composition data (epicatechin, epicatechin-3'-gallate, catechin and PA (dimers-hexamers)), even though differences in extraction procedures will lead to a significant variance in flavan-3-ol
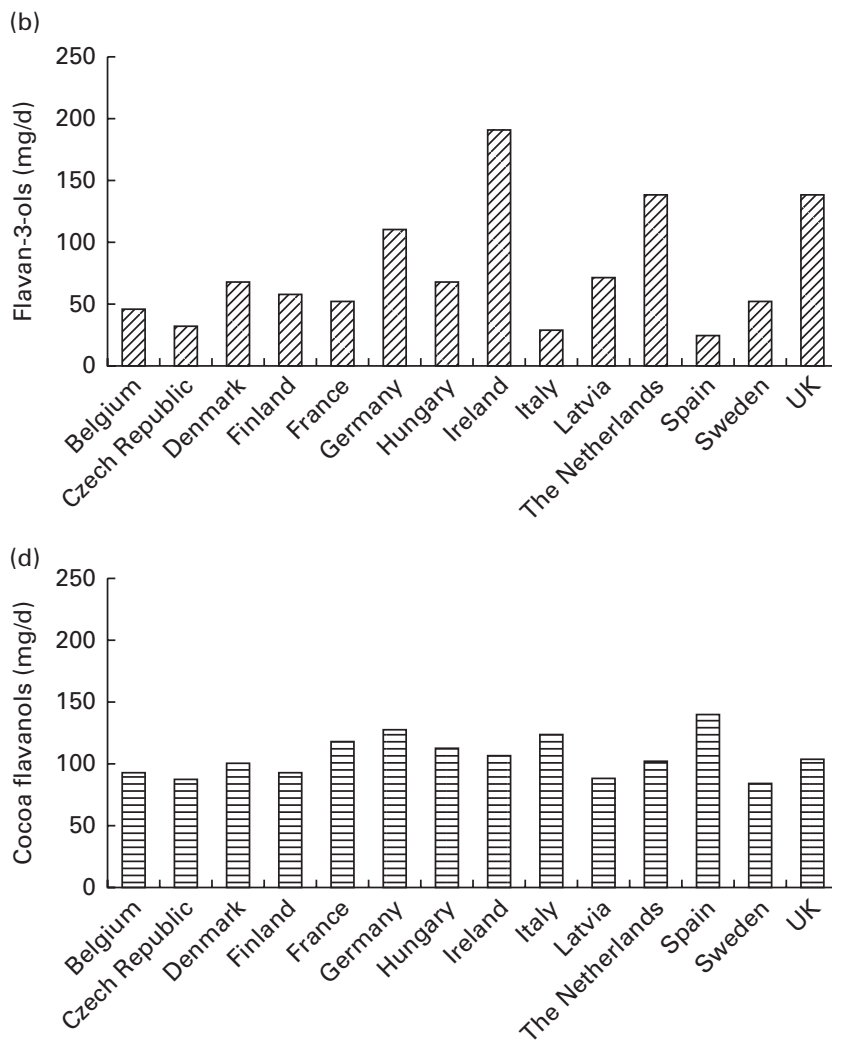

Fig. 4. Estimated mean intake (mg/d) of (a) total flavanols, (b) flavan-3-ols, (c) total procyanidins (PA) and (d) cocoa-flavanols $((-)$-epicatechin, $(+)$-catechin and PA (dimers-decamers)) for adults in the EFSA (European Food Safety Authority) Comprehensive European Food Consumption Database. 
content. Applying the definition provided above, it was found that the intake of cocoa flavanols in Europe varied from $84 \mathrm{mg} / \mathrm{d}$ (Sweden) to $138 \mathrm{mg} / \mathrm{d}$ (Spain), with an average value of $105 \mathrm{mg} / \mathrm{d}$, an amount well below that used in many intervention studies (mean $550 \mathrm{mg} / \mathrm{d}^{(3)} ;$ Fig. 4). The intake of grape seed flavanols was lower, with an average value of $98 \mathrm{mg} / \mathrm{d}(70 \mathrm{mg} / \mathrm{d}$ in the Czech Republic to $132 \mathrm{mg} / \mathrm{d}$ in Ireland), which is also well below the amount used in intervention studies $\left(150-2000 \mathrm{mg} / \mathrm{d}^{(9)}\right)$. Thus, on the one hand, it seems that the intake of flavan-3-ols in Europe is well below the intake levels thus far established in the context of dietary interventions to be required to observe beneficial cardiovascular effects. Moreover, most Europeans consume less than $50 \%$ of the $200 \mathrm{mg}$ of cocoa flavanols per d considered by the EFSA to be sufficient for improved vascular function and less than $25 \%$ of the $400 \mathrm{mg} / \mathrm{d}$ required to observe a reduction of systolic blood pressure ${ }^{(41)}$. On the other hand, only the intake of one member of the cocoa flavanol group, namely (-)-epicatechin, has thus far been reported to be directly and causally linked to the modulation of vascular function (flow-mediated dilation) ${ }^{(42,43)}$ Recent data also demonstrate that while (-)-epicatechin is absorbed and present as a phase II metabolite in the systemic circulation, the absorption of procyanidins (DP 2-10) in humans is negligible and that these compounds do not contribute to the systemic pool of flavanol metabolites ${ }^{(40)}$. Thus, if one were to interpret the opinion of the EFSA on cocoa flavanols based on the intake of (-)-epicatechin alone, the intake of $200 \mathrm{mg}$ of cocoa flavanols (DP 1-10) would deliver between 15 and $25 \mathrm{mg}$ of (-)-epicatechin, an amount that many Europeans already consume as part of their daily diet, thus weakening the arguments for food benefit claims at intake levels of $200 \mathrm{mg} / \mathrm{d}$. Nevertheless, various other questions and knowledge gaps exist in this context (influence of age, sex, dietary background and ethnicity on flavanol intake/benefits), and further research is necessary before the results from controlled interventions studies can be meaningfully translated into the context of primary prevention, public health and evidencebased dietary recommendations. Such efforts will require not only a more consistent application of flavanol nomenclature and a better characterisation of foods used in dietary interventions, but also improved methods for dietary assessment, such as nutritional biomarkers. Only a combination of data from intervention studies and those from observational studies will ultimately enable a comprehensive assessment of the impact of flavan-3-ol intake on public health.

\section{Supplementary material}

To view supplementary material for this article, please visit http://dx.doi.org/10.1017/S0007114513003930

\section{Acknowledgements}

The authors thank all the EPIC-Norfolk study participants and staff for their contribution to the study. They also thank the members of the FLAVIOLA consortium for their critical review of the manuscript.
The present study was supported by the EU (grant 226588, 'Flaviola') and an unrestricted grant from Mars, Inc. Mars, Inc. had no role in the design and analysis of the study or in the writing of this article.

The authors' contributions are as follows: A. V. conducted the research, analysed the data and wrote the article; A. A. M., R. N. L. and M. A. H. L. conducted the research, analysed the data and contributed to manuscript preparation; C. H., M. K., M. W. M., J. P. E. S. and H. S. analysed the data and contributed to manuscript preparation; G. G. C. K. wrote the manuscript and had primary responsibility for the final content. All authors read and approved the final manuscript.

H. S. is employed by MARS, Inc, a member of the FLAVIOLA research consortium and a company engaged in flavanol research and flavanol-related commercial activities. None of the other authors has a conflict of interest to declare.

\section{References}

1. Schroeter H, Heiss C, Spencer JPE, et al. (2010) Recommending flavanols and procyanidins for cardiovascular health: current knowledge and future needs. Mol Aspects Med 31, 546-557.

2. Ellinger S, Reusch A, Stehle P, et al. (2012) Epicatechin ingested via cocoa products reduces blood pressure in humans: a nonlinear regression model with a Bayesian approach. Am J Clin Nutr 95, 1365-1377.

3. Ried K, Sullivan T, Fakler P, et al. (2012) Effect of cocoa on blood pressure. Cochrane Database Syst Rev issue 8, CD008893.

4. EFSA Panel on Dietetic Products, Nutrition and Allergies (NDA) (2012) Scientific opinion on the substantiation of a health claim related to cocoa flavanols and maintenance of normal endothelium-dependent vasodilation pursuant to Article 13(5) of Regulation (EC) No. 1924/2006. EFSA J 10, 2809-2830.

5. Santos-Buelga C \& Scalbert A (2000) Proanthocyanidins and tannin-like compounds: nature, occurrence, dietary intake and effects on nutrition and health. J Sci Food Agric 80, 1094-1117.

6. Manach C, Williamson G, Morand C, et al. (2005) Bioavailability and bioefficacy of polyphenols in humans. I. Review of 97 bioavailability studies. Am J Clin Nutr 81, 230S-242S.

7. Cassidy A, Rimm EB, O'Reill EJ, et al. (2012) Dietary flavonoids and risk of stroke in women. Stroke 43, 946-951.

8. Cassidy A, O'Reilly EJ, Kay C, et al. (2011) Habitual intake of flavonoid subclasses and incident hypertension in adults. Am J Clin Nutr 93, 338-347.

9. Feringa HHH, Laskey DA, Dickson JE, et al. (2011) The effect of grape seed extract on cardiovascular risk markers: a metaanalysis of randomized controlled trials. J Am Diet Assoc 111, 1173-1181.

10. Chun OK, Chung SJ \& Song WO (2007) Estimated dietary flavonoid intake and major food sources of U.S. adults. $J$ Nutr 137, 1244-1252.

11. Johannot L \& Somerset SM (2006) Age-related variations in flavonoid intake and sources in the Australian population. Public Health Nutr 9, 1045-1054.

12. Justesen U, Knuthsen P \& Leth T (1997) Determination of plant polyphenols in Danish foodstuffs by HPLC-UV and LC-MS detection. Cancer Lett 114, 165-167.

13. Wang Y, Chung SJ, Song WO, et al. (2011) Estimation of daily proanthocyanidin intake and major food sources in the U.S. diet. J Nutr 141, 447-452. 
14. Arts IC, Hollman PC, Feskens EJ, et al. (2001) Catechin intake and associated dietary and lifestyle factors in a representative sample of Dutch men and women. Eur J Clin Nutr 55, $76-81$.

15. Hertog MG, Hollman PC, Katan MB, et al. (1993) Intake of potentially anticarcinogenic flavonoids and their determinants in adults in The Netherlands. Nutr Cancer 20, 21-29.

16. Arai Y, Watanabe S, Kimira M, et al. (2000) Dietary intakes of flavonols, flavones and isoflavones by Japanese women and the inverse correlation between quercetin intake and plasma LDL cholesterol concentration. J Nutr 130, 2243-2250.

17. Chun O, Kim D-O, Smith NL, et al. (2005) Daily consumption of phenolics and total antioxidant capacity from fruit and vegetables in the American diet. J Sci Food Agric 85, $1715-1724$

18. Hertog MG, Feskens EJ, Hollman PC, et al. (1993) Dietary antioxidant flavonoids and risk of coronary heart disease: the Zutphen Elderly Study. Lancet 342, 1007-1011.

19. Hertog MG, Kromhout D, Aravanis C, et al. (1995) Flavonoid intake and long-term risk of coronary heart disease and cancer in the seven countries study. Arch Intern Med 155, 381-386.

20. Knekt P, Jarvinen R, Reunanen A, et al. (1996) Flavonoid intake and coronary mortality in Finland: a cohort study. BMJ 312, 478-481.

21. Knekt P, Kumpulainen J, Jarvinen R, et al. (2002) Flavonoid intake and risk of chronic diseases. Am J Clin Nutr 76, 560-568.

22. Sampson L, Rimm E, Hollman PC, et al. (2002) Flavonol and flavone intakes in US health professionals. J Am Diet Assoc 102, 1414-1420.

23. Knaze V, Zamora-Ros R, Lujan-Barroso L, et al. (2012) Intake estimation of total and individual flavan-3-ols, proanthocyanidins and theaflavins, their food sources and determinants in the European Prospective Investigation into Cancer and Nutrition (EPIC) study. Br J Nutr 108, 1095-1108.

24. Neveu V, Perez-Jimenez J, Vos F, et al. (2010) PhenolExplorer: an online comprehensive database on polyphenol contents in foods. Database (Oxford) 2010, bap024.

25. USDA (2007) USDA Database for the Proanthocyanidin Content of Selected Foods. Beltsville, MD: US Department of Agriculture.

26. USDA (2011) USDA Database for the Flavonoid Content of Selected Foods. Beltsville, MD: US Department of Agriculture.

27. EFSA The EFSA Comprehensive European Food Consumption Databasehttp://wwwefsaeuropaeu/en/datexfoodcdb/datex fooddbhtm.2011

28. EFSA (2011) Food Classification. http://wwwefsaeuropaeu/ en/datex/datexfoodclasshtm?wtrl $=01.2011$

29. Welch AA, McTaggart A, Mulligan AA, et al. (2001) DINER (Data Into Nutrients for Epidemiological Research) - a new data-entry program for nutritional analysis in the EPIC-Norfolk cohort and the 7-day diary method. Public Health Nutr 4, 1253-1265.
30. Crozier A, Lean M, McDonald M, et al. (1997) Quantitative analysis of the flavonoid content of commercial tomatoes, onions, lettuces, and celery. J Agric Food Chem 45, 590-595.

31. Lentjes MAH, McTaggart A, Mulligan AA, et al. (2013) Dietary intake measurement using $7 \mathrm{~d}$ diet diaries in British men and women in the European Prospective Investigation into Cancer-Norfolk Study: a focus on methodological issues. Br J Nutr (epublication ahead of print version 17 September 2013).

32. Holland B, Welch AA, Unwin I, et al. (1991) McCance and Widdowson's The Composition of Foods, 5th ed. London: Royal Society of Chemistry/Ministry of Agriculture, Fisheries and Food.

33. Kaaks R \& Riboli E (1997) Validation and calibration of dietary intake measurements in the EPIC project: methodological considerations. European Prospective Investigation into Cancer and Nutrition. Int J Epidemiol 26, Suppl. 1, S15-S25.

34. Slimani N, Kaaks R, Ferrari P, et al. (2002) European Prospective Investigation into Cancer and Nutrition (EPIC) calibration study: rationale, design and population characteristics. Public Health Nutr 5, 1125-1145.

35. Robbins RJ, Leonczak J, Li J, et al. (2012) Determination of flavanol and procyanidin (by degree of polymerization 1-10) content of chocolate, cocoa liquors, powder(s), and cocoa flavanol extracts by normal phase high-performance liquid chromatography: collaborative study. J AOAC Int $\mathbf{9 5}$, 1153-1160.

36. Otaki N, Kimira M, Katsumata S, et al. (2009) Distribution and major sources of flavonoid intakes in the middle-aged Japanese women. J Clin Biochem Nutr 44, 231-238.

37. Perez-Jimenez J, Fezeu L, Touvier M, et al. (2011) Dietary intake of 337 polyphenols in French adults. Am J Clin Nutr 93, $1220-1228$.

38. Zamora-Ros R, Andres-Lacueva C, Lamuela-Raventos RM et al. (2010) Estimation of dietary sources and flavonoid intake in a Spanish adult population (EPIC-Spain). $J \mathrm{Am}$ Diet Assoc 110, 390-398.

39. Ottaviani JI, Momma TY, Heiss C, et al. (2011) The stereochemical configuration of flavanols influences the level and metabolism of flavanols in humans and their biological activity in vivo. Free Radic Biol Med 50, 237-244.

40. Ottaviani JI, Kwik-Uribe C, Keen CL, et al. (2012) Intake of dietary procyanidins does not contribute to the pool of circulating flavanols in humans. Am J Clin Nutr 95, 851-858.

41. Hooper L, Kay C, Abdelhamid A, et al. (2012) Effects of chocolate, cocoa, and flavan-3-ols on cardiovascular health: a systematic review and meta-analysis of randomized trials. Am J Clin Nutr 95, 740-751.

42. Schroeter H, Heiss C, Balzer J, et al. (2006) (-)-Epicatechin mediates beneficial effects of flavanol-rich cocoa on vascular function in humans. Proc Natl Acad Sci U S A 103, 1024-1029.

43. Loke WM, Hodgson JM, Proudfoot JM, et al. (2008) Pure dietary flavonoids quercetin and (-)-epicatechin augment nitric oxide products and reduce endothelin-1 acutely in healthy men. Am J Clin Nutr 88, 1018-1025. 